\title{
RESENHA - AVALIAÇÃO: DIFERENTES PROCESSOS NO CONTEXTO EDUCACIONAL
}

\author{
ALESSANDRA RODRIGUES ${ }^{1}$
}

CALIATTO, Susana Gakyia; OLIVEIRA, Sandra Maria da Silva Sales; CUNHA, Neide de Brito; JOLY, Maria Cristina Rodrigues Azevedo (Orgs.), Avaliação: diferentes processos no contexto educacional. Uberlândia: Navegando Publicações, 2017, 360 p.

A temática da avaliação, por vezes árida e controversa, mas sempre essencial às discussões no campo educacional, é o centro do e-book organizado por Susana Caliatto, Sandra Oliveira, Neide Cunha e Maria Cristina Joly e publicado pela Editora Navegando. Em “Avaliação: diferentes processos no contexto educacional", as organizadoras, experientes investigadoras nas áreas da Educação e da Psicologia, apresentam estudos de pesquisadores brasileiros e portugueses que contribuem para o avanço das reflexões sobre a avaliação, em seus mais diversos contextos e aplicações, na medida em que acrescentam olhares articuladores de diálogos entre essas duas áreas.

A obra tem 360 páginas, nas quais se organizam treze capítulos, em uma apresentação gráfica que convida à leitura em tela, mas permite também o download do arquivo em formato PDF - o que também possibilita o estudo de capítulos impressos do livro. Nos capítulos, alguns de autoria das organizadoras, são abordados desde os aspectos cognitivos dos estudantes até o envolvimento dos pais e a atitude dos professores como elementos não somente centrais nos processos de ensino e aprendizagem, mas também no contexto das avaliações escolares em diferentes níveis de ensino. Assim, trata-se de uma obra que abarca um amplo espectro de possibilidades para se pensar e promover a avaliação tendo em vista as contribuições da psicologia educacional.

A organização dos capítulos se dá em três blocos que enfocam a perspectiva avaliativa tendo

1 Professora Doutora do Programa de Pós-Graduação em Educação em Ciências da Universidade Federal de Itajubá (Unifei). 
como centro, no primeiro conjunto de capítulos, os estudantes; no segundo bloco, o olhar dos pesquisadores se volta aos professores e seu papel nos processos de ensinar, aprender e avaliar. Finalmente, os últimos capítulos da obra destacam métodos de avaliação como componentes de reflexão crítica sobre a educação.

Partindo dessa organização, o primeiro capítulo, A avaliação das aptidões cognitivas para a promoção de percursos de sucesso: estudo com adolescentes portugueses, traz, como anuncia o título, dados do contexto português que podem iluminar também as reflexões de pesquisadores brasileiros sobre os desempenhos cognitivos dos jovens por meio de um novo instrumento de avaliação cognitiva. Os autores, Gina Claudia Lemos e Leandro da Silva Almeida, chamam a atenção para elementos pessoais e contextuais que constituem cada jovem em sua individualidade e interferem em seu desenvolvimento cognitivo. Uma das contribuições do capítulo é mostrar que a avaliação das habilidades cognitivas pode ser um recurso de autorregulação da aprendizagem e de promoção do sucesso escolar.

Essa mesma perspectiva, que entende a avaliação como uma possibilidade para auxiliar e promover o desenvolvimento dos estudantes, mas também de demonstração de habilidades e aprendizagem por estes sujeitos, orienta o estudo apresentado no segundo capítulo: Avaliação da aprendizagem por meio do teste de desempenho escolar em uma amostra de escolares do interior da Bahia. Buscando contribuir para as discussões gerais sobre avaliação educacional, Adriana Cristina Boulhoça Suehiro e Maryana Gomes Pimentel ressaltam a importância de identificar aspectos relacionados ao desempenho escolar em contextos diversos. As autoras se dedicam a analisar e discutir os resultados da avaliação das habilidades de leitura, escrita e matemática de estudantes de Ensino Fundamental de uma região pouco desenvolvida do Brasil, identificando diferenças entre as crianças avaliadas no que se refere ao sexo, à série e à idade. Para Suehiro e Pimentel, essa identificação das habilidades reais dos estudantes permite, por parte dos professores, ações mais efetivas para solução das dificuldades próprias do processo de aprendizagem na escola.

O próximo capítulo, de Alessandra Rodrigues de Almeida e Maria Cristina Rodrigues Azevedo Joly, intitulado A avaliação da compreensão da linguagem oral de crianças em início de escolarização, volta-se à questão da avaliação das habilidades linguísticas, destacando a importância das avaliações prévias para identificação de problemas de linguagem e para que a intervenção consequente seja adequada ao nível de cada estudante no processo de alfabetização. As autoras lançam mão da Bateria Informatizada de Linguagem Oral - BILO (JOLY, 2006) para realizar o estudo, apontando que este 
instrumento tem características adequadas à avaliação da compreensão da linguagem oral em crianças em início de escolarização. Assim, as contribuições de Almeida e Joly nesse capítulo alcançam a avaliação psicoeducacional e da linguagem, oferecendo instrumentos importantes ao contexto brasileiro neste aspecto.

Também o quarto capítulo, Compreensão de leitura e sua relação com raciocínio verbal, volta-se às questões da linguagem. As autoras, Thatiana Helena de Lima e Acácia Aparecida Angeli dos Santos, apontam os baixos índices de habilidades leitoras alcançados pelos estudantes brasileiros em avaliações de larga escala e, a partir daí, apresentam resultados de estudos que mostram a correlação entre a inteligência e a compreensão leitora. Assim, o capítulo contribui para compreendermos o raciocínio como um elemento da leitura e, consequentemente, da aprendizagem significativa.

O estudo de Jussara Cristina Barboza Tortella é apresentado no quinto capítulo: Um projeto de autorregulação em salas do ensino fundamental. O texto instiga o leitor a repensar paradigmas sobre autorregulação de aprendizagem somente voltada a adultos ao apresentar e discutir dados de três pesquisas desenvolvidas com crianças do quinto ano do Ensino Fundamental de escolas municipais de cidades do interior de São Paulo. A autora discute a temática da autorregulação da aprendizagem por meio da apresentação da metodologia e do desenvolvimento do Programa "As Travessuras do Amarelo". Após participarem do Programa, os estudantes mostraram, segundo Tortella, mudanças de percepção e de envolvimento com a própria aprendizagem, movimentos de autoavaliação e alterações de atitude em relação ao desempenho acadêmico, além de outros aspectos.

Completando o bloco de capítulos com foco nos estudantes, no sexto capítulo, Envolvimento parental na educação, recursos do ambiente familiar e desempenho acadêmico de crianças, o papel dos pais na avaliação dos processos de aprendizagem dos filhos é colocado em foco por Júlio Antônio Moreira Gomes e Neide de Brito Cunha. O texto traz importantes contribuições ao apontar, a partir de constructos teóricos e empíricos, que o desenvolvimento da criança, em suas múltiplas dimensões, tem como condicionante a participação regular e constante dos pais ou responsáveis nas atividades educacionais. Assim, os autores refletem sobre a importância da articulação entre a escola, a família e a comunidade para promover o desenvolvimento integral da criança.

O bloco de capítulos cujos estudos se voltam ao papel do professor na avaliação é aberto com o capítulo sete: Atitude docente e o impacto sobre o ensino, escrito por Eli Andrade Rocha Prates e Maria Cristina Rodrigues Azevedo Joly. Os autores têm como locus de investigação o contexto do Ensino Superior no Brasil e refletem sobre a relação professor-aluno, tendo como ponto de partida e 
de chegada a ideia de que esta relação é mediada pelas competências (cognitivas, afetivas, técnicas) do docente e pela percepção de tais competências pelos alunos. No contexto universitário, o capítulo se torna ainda mais relevante por lançar luz sobre uma temática que costuma ser diminuída na formação superior: a associação entre relações humanas e ensino como promotora de aprendizagens. Os resultados do estudo contribuem para a defesa da ideia de que a afetividade faz parte dos processos de ensinar e aprender e, por isto, deve também ser tema da formação de professores e da prática docente cotidiana.

O capítulo seguinte, Representações de professores do ensino fundamental sobre as variáveis que influenciam o desempenho escolar, de Andréia Osti, também abarca a relação professor-aluno, mas agora no Ensino Fundamental. A autora busca conhecer o ponto de vista dos docentes sobre: a) o processo de aprendizagem por meio do desempenho escolar e, b) as variáveis determinantes do sucesso ou do fracasso na aprendizagem. Os resultados da pesquisa mostram uma relação direta e bastante fidedigna entre as representações dos professores e a realidade do contexto escolar. Além disso, indicam que as representações docentes são percebidas e têm efeitos sobre os alunos e suas percepções, interpretações e reações quanto à aprendizagem. A relevância do estudo está justamente em expor a inter-relação, por um lado, das representações docentes com as práticas pedagógicas e, por outro, destas representações com o processo de aprendizagem dos estudantes.

Michele Correa Freitas Soares e Rosimeire Aparecida Soares Borges também orientam o estudo que origina o capítulo nove, Avaliação das concepções dos professores do ensino fundamental I sobre uso de software, pela ideia de que as representações e crenças docentes são estruturantes e, ao mesmo tempo, transformadoras de contextos e paradigmas educacionais. As autoras apresentam estudo que buscou conhecer as concepções de professores sobre o uso pedagógico das tecnologias. Em uma análise crítica e contextualizada dos dados, Soares e Borges apontam a importância da valorização intelectual dos docentes e da formação de professores para o uso pedagógico e significativo das tecnologias digitais de nosso tempo; já que, apesar de reconhecerem a importância destas tecnologias para as práticas pedagógicas, os professores ainda têm certa desconfiança e desconforto com o recurso tecnológico. Assim, antes de investimentos em equipamentos e suporte, as autoras defendem a importância de se investir em formação e valorização docente no país.

O décimo capítulo finaliza o bloco dedicado à relação professor-avaliação e intitula-se Avaliação institucional e monitoramento da qualidade da educação superior. Os autores, Neide Pena Cária e Nelson Lambert de Andrade, discutem aspectos da avaliação institucional no Ensino Superior. 
Contextualizando criticamente a temática, Cária e Andrade a situam como uma questão política - e não apenas técnica - e tratam da autoavaliação tanto como estratégia de acompanhamento da qualidade dos serviços educacionais prestados pelas instituições - no âmbito do Ensino Superior - como também enquanto instrumento da própria avaliação institucional. Os autores concluem o capítulo defendendo que a avaliação institucional no Brasil ainda carece de aprimoramentos para se consolidar como "cultura de avaliação" e superar a lógica simplista de ser vista como mero instrumento de controle e punição.

O último bloco de capítulos tem como eixo a apresentação e discussão de trabalhos de avaliação realizados em diferentes contextos educacionais. $O$ capítulo intitulado $\mathbf{O}$ processo de ensinoaprendizagem e as dificuldades de mensurá-lo por meio de avaliações quali-quantitativas no ensino superior: perspectivas atuais, de Luís Henrique Sales Oliveira e Sandra Maria da Silva Sales Oliveira, abre o bloco derradeiro. Os autores abordam a avaliação de conteúdos no Ensino Superior e as dificuldades encontradas pelos professores para estabelecer critérios para a realização de avaliações tanto em sala de aula quanto nos campos de estágio curricular. O capítulo apresenta a avaliação como fator basilar para o monitoramento dos processos de ensino e aprendizagem. Entretanto, ressaltam as dificuldades de mensuração da aprendizagem dos estudantes no Ensino Superior e questionam se tais dificuldades não seriam decorrentes de uma formação fortemente tecnicista, estratificada e cada vez menos global. As contribuições do capítulo estão especialmente nas reflexões críticas feitas pelos autores e na atualização que oferecem aos leitores sobre diferentes estratégias de avaliação para o contexto universitário.

O capítulo doze - de Wlahilma Maria de Queiroz Bezerra, Bento Duarte Silva e João Batista Carvalho Nunes - corrobora as ideias do anterior, buscando novos olhares para a avaliação de conteúdos no Ensino Superior, tendo como locus de investigação um curso de licenciatura a distância de uma universidade do Nordeste do brasileiro. Avaliar sob a perspectiva da gestão do fazer docente: desvendando caminhos da avaliação da aprendizagem na educação online trata da avaliação como um instrumento de "gestão do fazer docente". Assim, os autores defendem que, ao avaliar o aluno, o professor também se autoavalia e se reconstrói, numa práxis dialógica - professor-aluno - que contribui para o autoconhecimento de ambos os atores da cena escolar. Além das reflexões teóricas, o capítulo traz como contribuição a apresentação de diversas modalidades de avaliação realizadas no curso de licenciatura a distância por meio de tecnologia digital móvel sem fio e aponta que a experiência gerou aproximação e empatia entre professores e alunos do curso. 
O último capítulo da obra é escrito por Ronei Ximenes Martins e Juliana de Freitas Azevedo e se intitula Avaliação de projetos de trabalho por meio da observação participante e roteiros estruturados: um estudo de caso. Os autores apresentam resultados de pesquisa estruturada a partir da perspectiva da Pedagogia de Projetos. Martins e Azevedo, além das contribuições oriundas dos dados da pesquisa, também trazem significativa colaboração à área da educação com as reflexões metodológicas e o percurso de sua investigação. A apresentação detalhada da estratégia de avaliação aplicada pelos autores com enfoque em uma ação educativa multidisciplinar enfatiza as contribuições da observação estruturada para acompanhar e avaliar atitudes, aprendizagens e uso de tecnologias em contexto educacional.

Em todos os capítulos desta obra fica clara a centralidade das figuras do aluno e do professor nos processos de avaliação como sujeitos crítico-reflexivos. $\mathrm{O}$ caráter abrangente e multirreferencial dos estudos também merece nota. Apesar da profundidade teórica dos estudos, a linguagem acessível utilizada pelos autores convida à leitura e torna o livro indicado tanto a profissionais das áreas da Educação e da Psicologia, como a estudantes e público interessado na temática da avaliação em suas diferentes facetas e contextos de realização.

Recebido em: $17 / 10 / 2017$

Aprovado em: 06/11/2017 